\title{
Audit of the investigation of iron deficiency anaemia in a district general hospital, with sample guidelines for future practice
}

\author{
J M T Willoughby, S M Laitner
}

\begin{abstract}
Iron deficiency anaemia commonly presents in patients who are asymptomatic. In the absence of published guidelines the search for a cause in such cases is frequently uncoordinated, and risks delay in the diagnosis of pathologies requiring urgent attention. This audit was undertaken to determine how thoroughly patients referred to the gastrointestinal unit in a district general hospital between 1990 and 1995 had been investigated, and to draw up guidelines for future practice on the basis of its results. From the case notes of 334 patients examined endoscopically for anaemia 126 were identified as having both proved iron deficiency and a lack of clinical pointers to its cause. The percentage and details of diagnoses made during initial study and a median follow up period of 28 months were ascertained, together with the certified diagnoses of patients who had died. A cause of iron deficiency was identified in $48(38 \%)$ of patients, 22 with cancer. Ten others received a diagnosis during follow up, of whom three died from the condition to which their anaemia had been attributed. Death certificates supplied diagnoses of potential relevance in three further cases. The main gaps in endoscopic coverage consisted of omitting duodenal biopsy or colonoscopy after negative upper gastrointestinal endoscopy. Moreover, diagnosis of certain extraintestinal pathologies, including cancers, was sometimes delayed for lack of liaison between gastroenterologists and other specialists. These and other points have been addressed in the guidelines now proposed.

(Postgrad Med f 2000;76:218-222)
\end{abstract}

Keywords: audit; investigation; iron deficiency anaemia; guidelines

Department of Medicine, Lister Hospital, Stevenage, Herts SG1 4AB, UK J M T Willoughby

S M Laitner

Correspondence to: Dr Willoughby

Submitted 1 June 1999 Accepted 13 August 1999

Prospective studies in the investigation of iron deficiency anaemia have shown that this is associated with a high frequency of gastrointestinal lesions. ${ }^{1-6}$ Some protocols have included formal dietary assessment to estimate the contribution of poor iron intake, ${ }^{124}$ but none has been designed to explore also the role of excess menstrual loss in a population routinely referred for endoscopy. Other extraintestinal causes of occult iron deficiency are probably rare, but carcinoma of the bladder has been reported as a late finding after negative gastrointestinal studies, ${ }^{2}$ and in a district-wide survey, which excluded women under 50 years of age, bleeding lesions of the urinary tract predominated. $^{7}$

It is doubtful whether many hospitals have yet considered establishing a policy for the investigation of iron deficiency anaemia. Our hospital offers no guidance on this subject, and the present audit was undertaken to determine whether the absence of a policy and the effective assumption by the gastrointestinal unit of responsibility for finding its cause in most cases was conducing to poor practice. Since the anaemia in such cases had usually been an unexpected finding we chose to confine the study to those in which no hint as to its origin had emerged from prior work-up.

\section{Patients and methods}

PATIENTS

The case notes of 334 patients recorded as having undergone endoscopy for anaemia between 1 March 1990 and 28 February 1995 were searched for evidence of iron deficiency, but also for any aspect of the history, physical signs, or tests already completed which could have suggested to the endoscopist the site or nature of the causative lesion, and would therefore disqualify the case for this study. Excluded thus was any case in which the patient had admitted taking non-steroidal antiinflammatory drugs within the past three months.

Anaemia was defined by a haemoglobin concentration of $<120 \mathrm{~g} / 1$ in males, $<115 \mathrm{~g} / 1$ in females, and was accepted as being due to iron deficiency if accompanied by a mean corpuscular volume of $<80 \mathrm{fl}$ and either a serum ferritin of $<10 \mu \mathrm{g} / 1$ or a response to iron repletion.

\section{INVESTIGATIONS}

The dates and results of all endoscopies, contrast radiographs, and radioisotope scans carried out as part of a single programme of investigation, begun or completed during the five year study period, were recorded. Any clinician responsible for a patient's care might have initiated a programme without seeking gastroenterological advice, but once endoscopy had been performed almost all subsequent tests were chosen by the specialist concerned. 
FOLLOW UP OF UNDIAGNOSED PATIENTS

Data were taken from case notes or sought from general practitioners on a standard questionnaire. Copies of the death certificates were obtained for patients who had died outside hospital.

\section{Results}

CASES STUDIED

The inclusion criteria were met in 126 (38\%) cases. Of the patients qualifying 84 , that is two thirds, were female. The age range was 15-94 (median 70).

DIAGNOSES

"Diagnosis" was defined as the discovery of any lesion that could be considered definitely or probably the cause of a patient's anaemia. Such diagnoses were made in 48 (38\%) patients. They included four of extraintestinal conditions (menorrhagia in two cases, dietary iron deficiency and carcinoma of endometrium in one each), which were confirmed by the results of appropriate management. That of endometrial carcinoma was made by a gynaecologist asked to advise on the aetiology of a nonhaemorrhagic vaginal discharge.

Table 1 lists the diagnoses by age group. The rare finding of an oesophagogastric haemangioma was the only instance in which a potential bleeding lesion of the upper gastrointestinal tract occurred in a patient less than 65 years of age. The 22 malignancies constituted $45 \%$ of all diagnoses. Of these 15 were colonic, with the distribution: caecum (7), ascending colon (2), transverse colon (2), and sigmoid colon (4).

Diagnoses considered as only possible causes of the iron deficiency, and therefore excluded from analysis, were: gastritis (8), oesophagitis (6), colonic polyps of less than $1 \mathrm{~cm}$ diameter (3), marginal dietary iron intake (2), bulbar duodenitis, non-specific duodenal villous abnormalities, third degree haemorrhoids, and malignant cachexia (one case each).

Pathology of at least possible relevance in both upper gastrointestinal tract and colon was found in five instances. In all upper gastrointestinal endoscopy had been the first proce- dure, showing a healing chronic gastric ulcer in one patient as the only lesion considered likely to have contributed to the anaemia. The other upper gastrointestinal findings comprised oesophagitis in one case, gastritis in another, and duodenitis in two. Four of the colonic lesions were carcinomas (in patients aged 64, 71,77 , and 80 ), one polyposis in a 68 year old. The combination of oesophagitis with gastric antral erosions was rejected as the cause of one patient's anaemia two weeks before she was found to have endometrial carcinoma.

SITE OF PATHOLOGY RELATED TO AGE AND

CHOICE OF PROCEDURE

Since in the group of patients up to age 44 all except one of the five gastrointestinal tract diagnoses were of coeliac disease and the other a jejunal leiomyosarcoma, neither colonoscopy nor barium enema proved positive in the 13 examinations of large bowel to which 12 of the 21 patients were subjected.

In the group aged 45-64, however, five out of nine gastrointestinal lesions were colonic. One of the four caecal carcinomas was identified by small bowel meal in a patient for whom this had been requested before any formal large bowel study. The age of the patient with polyposis coli was 60, and those of the patients with carcinoma 45, 57, 62, and 64 respectively.

Seven of the 16 diagnoses among patients aged $65-74$ were made by colonoscopy, and two by barium enema. In one further case a carcinoma of the distal transverse colon was missed at colonoscopy but discovered on colonic follow through of the subsequent small bowel meal. The six remaining diagnoses in this group were made at upper gastrointestinal endoscopy.

Among patients over 75 the discovery of a colonic lesion was due more often to barium enema (five cases) than to colonoscopy (three cases), probably because the radiography was preferred for 22 of the 33 large bowel studies in this group. A relevant lesion of the upper gastrointestinal tract was found at one in seven endoscopies.

Table 1 Diagnoses by age group

\begin{tabular}{lllll}
\hline & \multicolumn{1}{l}{ Age group } & & & \\
\cline { 2 - 5 } & $<44(n=21)$ & $45-64(n=28)$ & $65-74(n=33)$ & $>75(n=44)$ \\
\hline Diagnoses & Coeliac disease & Oesophagogastric haemangioma & Ca stomach & Oesophageal ulcer \\
& Coeliac disease & Coeliac disease & Ca stomach & Oesophageal candidiasis \\
& Coeliac disease & Coeliac disease & Ca stomach & Ca stomach \\
& Coeliac disease & Leiomyosarcoma jejunum & Gastric adenomas & Gastric ulcer \\
& Leiomyosarcoma jejunum & Colonic polyps & Gastric ulcer & Gastric ulcer \\
& Dietary deficiency & Ca colon & Duodenal ulcer & Duodenal ulcer \\
& Menorrhagia & Ca colon & Colonic polyps & Colonic polyps \\
& & Ca colon & Colonic polyps & Ca colon \\
& & Ca colon & Colonic polyps & Ca colon \\
& & Menorrhagia & Colonic polyps & Ca colon \\
& & & Colonic polyps & Ca colon \\
& & & Ca colon & Ca colon \\
& & & Ca colon & Ca colon \\
& & & Ca colon & Ca colon \\
No (\%) of patients & & & Ca colon & BLH \\
diagnosed & & & stomach/colon & Ca endometrium \\
\end{tabular}




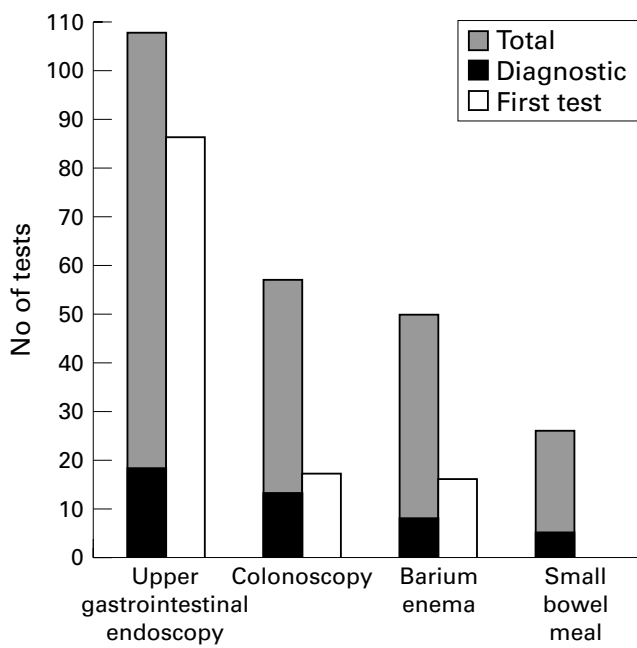

Figure 1 Number and diagnostic yield of the four principal procedures, with number of each performed as first procedure.

DIAGNOSTIC UTILITY OF INDIVIDUAL PROCEDURES Figure 1 shows how frequently each of the four main procedures was used, relating this both to diagnostic yield and to the number of patients for whom each had been chosen as the first examination. Percentage of diagnoses achieved was: colonoscopy 24, upper gastrointestinal endoscopy 17, small bowel meal 15, and barium enema 14. The disproportion between choice as first examination and diagnostic yield was most marked for upper gastrointestinal endoscopy. Other procedures comprised: radioisotope scan for Meckel's diverticulum (5), flexible sigmoidoscopy (3), and barium meal (1), none of which gave a diagnosis.

\section{PROCEDURES OMITTED}

There were 17 instances in which nondiagnostic upper gastrointestinal endoscopy was not followed by a colonic examination. Of these nine involved patients over 75, some of whom were stated to be too frail to undergo purgation and then a longer procedure. In four

Table 2 Follow up of anaemia, cause undetermined by initial investigations

\begin{tabular}{llll}
\hline State of anaemia & Resolved (n=33) & Controlled (n=21) & Persisting $(n=20)$ \\
\hline Median age at first test (range) & $69(31-93)$ & $71(15-89)$ & $70(19-94)$ \\
Median months follow up (range) & $30(7-75)$ & $27(5-69)$ & $25(1-73)$ \\
Still undiagnosed & 30 & 16 & 18 \\
Diagnoses given to remainder & Menorrhagia & Menorrhagia & Ca caecum \\
& Menorrhagia & Menorrhagia & Dietary deficiency \\
& Hypernephroma & Menorrhagia & \\
& & Dietary deficiency & \\
& & Ca bladder & \\
\hline
\end{tabular}

$\mathrm{Ca}=$ carcinoma

Table 3 Procedures performed and possibly relevant diagnosis at death in patients with initially undiagnosed cause of iron deficiency anaemia

\begin{tabular}{llll}
\hline \multicolumn{2}{l}{ Patients } & & \\
\cline { 1 - 2 } Sex & Age & Procedures & Certified diagnosis \\
\hline M & 75 & UGIE, colonoscopy, MDS & Ca bladder \\
$\mathrm{F}$ & 80 & UGIE, barium enema & Hypernephroma \\
$\mathrm{M}$ & 84 & UGIE, barium enema & Small bowel obstruction \\
$\mathrm{M}$ & 88 & UGIE & Carcinomatosis ? primary \\
$\mathrm{F}$ & 89 & UGIE & Gastroenteritis \\
$\mathrm{F}$ & 95 & UGIE, flexible sigmoidoscopy & Ca caecum \\
\hline
\end{tabular}

$\mathrm{Ca}=$ carcinoma; $\mathrm{MDS}=$ radioisotope scan for Meckel's diverticulum; UGIE = upper gastrointestinal endoscopy. cases a recommendation of colonoscopy was not taken up. In one colonoscopy was cancelled when the anaemia resolved, and in another the patient defaulted, leaving two patients under 45 whose investigation was presumably considered complete at this stage.

Upper gastrointestinal endoscopy was omitted after a normal colonic study in 12 patients. Of these four underwent no further investigation because their anaemia had resolved, menorrhagia had been diagnosed in another, and two patients declined the examination. No reason was given in the five remaining cases.

Duodenal biopsy was performed at only $42 \%$ of upper gastrointestinal endoscopies reported as showing no gross pathology.

FOLLOW UP OF UNDIAGNOSED PATIENTS

At the time of review $74(95 \%)$ of the 78 patients undiagnosed were either still attending the hospital, still on the list of the referring doctor, or known to have died with ascertainable diagnoses.

Median length of follow up was 28 months (range 1-75).

Table 2 shows that during follow up 10 patients were given a diagnosis which their doctors had accepted as the cause of their anaemia, leaving at least $64(51 \%)$ of the total 126 patients still undiagnosed. No less than half these late diagnoses were of menorrhagia, two of dietary iron deficiency, and three of carcinoma.

From table 2 it can also be seen that during follow up the anaemia had resolved in 33 of the 74 patients. In two this followed hysterectomy after a late diagnosis of menorrhagia, and in a third, with hypernephroma, resolution was unexplained. Anaemia therefore failed to recur in at least $30(47 \%)$ of patients for whom a potential cause was never identified.

Fifteen $(20 \%)$ of the patients had died. Table 3 relates possibly relevant diagnoses at death in six to the gastrointestinal procedures they had initially undergone. It seems unlikely that fuller investigation would have revealed the source of the anaemia in more than three of these. Two died after admission to hospital as emergencies, one with caecal carcinoma, the other with small bowel obstruction. The hypernephroma of a third would have been evident in an ultrasound scan. The only three definitive diagnoses included a second urinary tract carcinoma.

\section{Discussion}

Published figures for diagnostic yield in retrospective studies of the investigation of iron deficiency anaemia vary from $49 \%$ to $75 \%,{ }^{8-10}$ so that all seem to compare favourably with the $38 \%$ reported here. There would appear to be two main reasons for this. Firstly, the audit excluded patients who came to investigation with one or more clinical features suggesting a site for the causative pathology; secondly, we were unable to accept as potential causes of iron deficiency certain lesions of the upper gastrointestinal tract cited as such by other workers. Oesophagitis, gastritis, and duodenitis were excluded because never clearly haemorrhagic, and in no case were enough gastric ero- 
sions found to incriminate these as an important source of bleeding. The fact that even hiatus hernia, a non-haemorrhagic disorder, has been accepted by some authors ${ }^{12811}$ serves only to emphasise the extent to which figures for diagnostic yield in the investigation of iron deficiency depend on the significance attached to "borderline" pathology of the upper gastrointestinal tract. A recent quantitative study of gastrointestinal blood loss in patients with iron deficiency anaemia attributed to endoscopically diagnosed lesions found that only eight of 42 were losing more than $2 \mathrm{ml}$ daily. Only two of these had upper gastrointestinal pathology, and the patient losing least had ulcerative oesophagitis. $^{12}$

A few undiagnosed patients in the present series were inappropriately denied a complete endoscopic survey; and one, perhaps in this category but aged 95 at the time, died of caecal carcinoma two years after negative upper gastrointestinal endoscopy. In no case where major pathology was discovered at the first examination was it felt necessary to exclude a separate lesion elsewhere, and in none of these did such a lesion emerge at follow up. In this context it may be noted that important dual pathology has rarely been found in studies requiring that every patient should undergo examination of both upper gastrointestinal tract and colon. ${ }^{45}{ }^{13}$ It thus seems that a careful choice of first procedure and a conservative attitude to potentially causative pathology should together provide the basis for a safe minimum of gastrointestinal investigations.

Malabsorption of iron is one of the principal effects of damage to the mucosa in coeliac disease. In the present series all but one of the patients under 45 whose anaemia could be attributed to gastrointestinal pathology had coeliac disease, and there were two further cases in the next group, making a total of six $(5 \%)$. This frequency accords well with the $2 \%-6 \%$ found in other studies, ${ }^{46911}{ }^{14}$ although if recognised good practice had been followed routinely here, with biopsy of the duodenum whenever no gross lesion was found in the upper gastrointestinal tract, more cases might have been discovered. In formulating guidelines we have used the finding that in our study group coeliac disease was the only gastrointestinal condition associated with chronic anaemia to select patients giving this history - whatever their age - for upper gastrointestinal endoscopy as first examination.

Enteroscopy, extending access to the small bowel for inspection and biopsy, has an undoubted place in the investigation of iron deficiency anaemia, with a success rate of $20 \%$ in a recently reported study of 131 patients undiagnosed after routine endoscopy. ${ }^{15} \mathrm{Me}$ senteric angiography has also shown promise in a small series. ${ }^{16}$ Although the small bowel meal has disappointed elsewhere, ${ }^{569}$ it was in this instance the means by which two jejunal and two colonic cancers were diagnosed.

Of extraintestinal causes emerging in the present study dietary iron deficiency and menorrhagia were commonest, but referral of suspect cases for formal assessment was casual and slow. The Oxford survey of 371 patients, published in 1965, suggests that in the days before fibrendoscopy these possibilities were routinely pursued, and concludes that a diet deficient in iron was contributory in $19 \%$ of the entire group, menorrhagia in $37 \%$ of the women. ${ }^{11}$ The authors of a later study from Australia claimed that poor iron intake was a factor in over half their cases. ${ }^{1}$

Even before the coming of fibrendoscopy the prognosis for both resolution of the anaemia and survival without malignancy in patients whose condition had eluded diagnosis was excellent. ${ }^{11}$ More recently 30 of 36 such patients followed up for a mean 20 months were found to have recovered completely. The remainder had serious co-morbidity. ${ }^{5}$ A review of 83 patients with unexplained iron deficiency anaemia investigated during the period 1980-88 found that after a mean six years 10 had died of unrelated conditions and that in none had cancer been diagnosed. ${ }^{17}$ Few of the survivors were still taking iron supplements. Those in the majority whose anaemia had resolved in the absence of any detectable cause were held to have suffered from "transient cryptogenic iron deficiency anaemia", a diagnosis by exclusion which seems likely to hold true for more patients than any other. It applied to $47 \%$ of those who never received a positive diagnosis in the present series.

This audit supports the results of all previous studies in finding that lesions of the gastrointestinal tract account for most cases in which a cause is found for an iron deficiency anaemia presenting to hospital, and suggests that a sub-

Table 4 Sample guidelines for investigation of iron deficiency anaemia

\begin{tabular}{ll}
\hline $\begin{array}{l}\text { Programme A: for all patients } \\
\text { Patients } 45-74 \text { with recently diagnosed anaemia }\end{array}$ & - Colonoscopy. If no major lesion perform \\
$\begin{array}{c}\text { Patients }<45,>75 \text { with recently diagnosed anaemia } \\
\text { and }\end{array}$ & - Upper GI endoscopy/duodenal biopsy at same session \\
All patients with chronic anaemia & - Colonoscopy at same session in patients $>45$ \\
Colonoscopy incomplete & - Barium enema \\
Programme B: for patients still undiagnosed & \\
All patients & - Stop iron supplements \\
To complete investigation select from & - Full dietary history by dietitian \\
& - Gynaecological review for women menstruating \\
& - Renal ultrasound scan for patients $>50$
\end{tabular}




\section{Learning points}

- The investigation of iron deficiency anaemia is seldom pursued systematically; this can cause readily diagnosable cancers to be missed.

- Iron deficiency may be the sole presenting feature of coeliac disease, with its potential for causing ill health, which is reversible once the diagnosis has been made.

- All hospitals should adopt guidelines, arrived at by agreement between the relevant specialties, to ensure thorough investigation of iron deficiency anaemia.

stantial further group of cases may be attributed to dietary insufficiency of iron. The investigation of iron deficiency is, therefore, a task appropriately entrusted to the gastroenterologist. However, the frequency with which excess menstrual loss appeared as a diagnosis at follow up, and the more serious late diagnosis of two cancers of the urinary tract, indicate that this responsibility involves recognising when the expertise of another specialty is required. We suggest that the best way of ensuring satisfactory investigation of iron deficiency is for the appropriate specialties to agree guidelines which prescribe a sequence for gastrointestinal procedures and include any other measures that might be needed.

The sample scheme proposed here (table 4) assumes a lack of clinical pointers and allows for minimal work-up before endoscopy, though if the history given by a patient under 45 should hint at inadequate iron intake or excess menstrual loss it would be preferable to explore this possibility first. In the plan for endoscopy it distinguishes between patients on the grounds of our findings in relation to age and the known duration of the anaemia. This eliminates colonoscopy for patients under 45 and gives the elderly a chance to avoid it if, as is not uncommon, they have important pathology of the upper gastrointestinal tract that is clinically silent. The excessive use of upper gastro- intestinal endoscopy as first procedure implied by our results would therefore seem to apply chiefly to those patients aged between 45 and 74 , in whom neoplasia occurred more than three times as frequently in the colon as in the upper gastrointestinal tract. Colonoscopy is preferred to the combination of flexible sigmoidoscopy with barium enema because the former offers better diagnostic power at a single session and allows resection of polyps.

Any such scheme should be tested by prospective audit.

1 Kerlin P, Reiner R, Davies $\mathrm{M}$, et al. Iron-deficiency anaemia-a prospective study. Aust N Z F Med 1979;9:402-

2 Cook IJ, Pavli P, Riley JW, et al. Gastrointestinal investigation of iron deficiency anaemia. BMF 1986;292:1380-2.

3 Calvey HD, Castleden CM. Gastrointestinal investigations for anaemia in the elderly: a prospective study. Age Ageing 1987;16:399-404.

4 MacIntyre AS, Long RG. Prospective survey of investigations in outpatients referred with iron deficiency anaemia. Gut 1993; 34:1102-7.

5 Rockey DC, Cello JP. Evaluation of the gastrointestinal tract in patients with iron deficiency anemia. N Engl f Med 1993; 329:1691-5.

6 Kepczyk T, Kadakia SC. Prospective evaluation of gastrointestinal tract in patients with iron-deficiency anemia. Dig intestinal tract in patients
Dis Sci 1995;40:1283-9.

7 Lucas CA, Logan ECM, Logan RFA. Audit of the investigation and outcome of iron-deficiency anaemia in one health district. F R Coll Physicians Lond 1996;30:33-5.

8 Hershko C, Vitells A, Braverman DZ. Causes of iron deficiency anemia in an adult inpatient population. Effect of diagnostic workup on etiologic distribution. Blut 1984;49: 347-52.

9 Gordon SR, Smith RE, Power GC. The role of endoscopy in the evaluation of iron deficiency anemia in patients over the age of 50. Am ₹ Gastroenterol 1994;89:1963-7.

10 Till SH, Grundman MJ. Prevalence of concomitant disease in patients with iron deficiency anaemia. BMF 1997;314: in patient.

11 Beveridge BR, Bannerman RM, Evanson JM, et al. Beveridge BR, Bannerman RM, Evanson JM, et al.

12 Ferguson A, Brydon WG, Brian H, et al. Use of whole gut perfusion to investigate gastrointestinal blood loss in patients with iron deficiency anaemia. Gut 1996;38:120-4.

13 Bini EJ, Micale PL, Weinshel EH. Evaluation of the gastrointestinal tract in premenopausal women with iron deficiency anemia. Am f Med 1998;105:281-6.

14 Tobin MV, Gilmore IT. Gastrointestinal investigations of iron deficiency anaemia (letter). BMF 1986;292:1738.

15 Bouhnik Y, Bitoun A, Coffin B, et al. Two way push videoenteroscopy in investigation of small bowel disease. Gut 1998;43:280-4.

16 Lindsay JO, Taylor-Robinson SD, Walters JRF. Investigation of iron deficiency anaemia-a role for angiography (abof iron deficiency anaemia-a ro
stract). Gut 1997;41(suppl 3):A88.

17 Sahay R, Scott BB. Iron deficiency anaemia-how far to investigate? Gut 1993;34:1427-8. 


\section{LETTERS TO THE EDITOR}

\section{HIV infection and seizures}

EdIToR,-We read with interest the article from Dr Garg. ${ }^{1}$ We are just finishing a case-control study about risk factors for new onset seizures among HIV infected patients. All HIV infected patients hospitalised between 1 January 1992 and 31 March 1999 entered the study. Those suffering from any type of recent onset seizure were included as "cases". Two "controls" per case were randomly chosen matched by year of hospitalisation. Semiological type of seizure, CD4+ lymphocyte counts (dichotomised at $200 \mathrm{cells} / \mathrm{ml}$ ), HIV infection clinical stage (dichotomising $\mathrm{C} v \mathrm{~A}$ or $\mathrm{B}$ ), ${ }^{2}$ opportunistic HIV related central nervous system (CNS) diseases, CNS pathologies not related to HIV, age and sex, were registered.

Fifty four patients were included as cases. Their general clinical characteristics were in accordance with those of Garg's. Most of them had generalised tonic-clonic seizures (generalised 49, partial four, not classifiable one), and their causes, summarised in table 1 , were mostly in relation to opportunistic HIV related CNS diseases (36/54 cases). Nevertheless, CNS pathologies not related to HIV or with no specific cause could be identified in a significant number of cases (8/54 and 10/54 respectively). Patients

Table 1 Presumed aetiologies of new onset seizures in the 54 HIV infected patients included as cases in our study

\begin{tabular}{|c|c|c|c|}
\hline \multirow{2}{*}{\multicolumn{2}{|c|}{ CNS pathologies related to HIV }} & \multirow{2}{*}{\multicolumn{2}{|c|}{36}} \\
\hline & & & \\
\hline $\begin{array}{l}\text { Focal } \\
\text { Toxoplasmosis }\end{array}$ & 19 & 29 & \\
\hline $\begin{array}{l}\text { Lymphoma } \\
\text { Lyos }\end{array}$ & 6 & & \\
\hline $\begin{array}{l}\text { Progressive multifocal } \\
\text { leukoencephalopathy }\end{array}$ & 4 & & \\
\hline Diffuse & & 7 & \\
\hline HIV encephalopathy & 5 & & \\
\hline Tuberculous meningitis & 1 & & \\
\hline Encephalitis & 1 & & \\
\hline CNS pathologies not related & IIV & & 8 \\
\hline Infectious endocarditis & 2 & & \\
\hline Cranioencephalic traumatism & 2 & & \\
\hline Cerebrovascular & 1 & & \\
\hline Neurosyphilis & 1 & & \\
\hline Foscarnet therapy & 1 & & \\
\hline Glioma & 1 & & \\
\hline Idiopathic & & & 10 \\
\hline
\end{tabular}

generally showed considerable immunosuppression (CD4+ counts $<200$ cells $/ \mathrm{ml}$ in $93 \%$ of cases), and had previously suffered from other AIDS defining pathologies (86.5\%).

We hypothesised that immunosuppression, HIV clinical stage, and CNS HIV related opportunistic diseases were independent seizure risk factors. Crude univariate and multivariate analyses were done by means of Fisher's exact test and logistic regression and the results, summarised in table 2, were expressed as odds ratios with the corresponding 95\% confidence interval and Fisher's exact test or likelihood ratio $\mathrm{p}$ values (SPSS 8.0 for Windows).

Crude univariate analysis disclosed that immunosuppression, HIV clinical stage, and several CNS HIV related opportunistic diseases behaved as important risk factors, as well as CNS pathologies unrelated to HIV, analysed as a group, did. However, when dichotomised CD4+ lymphocytes counts, HIV clinical stage, and relevant CNS pathologies were simultaneously introduced, in conjunction with sex and age as potential confounders, in a logistic regression model, immunosuppression and HIV infection clinical stage lost all their influence, while the effect of most HIV related CNS opportunistic diseases was maintained or even enhanced, in the same way as occurred with $\mathrm{CNS}$ pathologies unrelated to HIV.

Neither immunosuppression nor HIV clinical stage behave as independent risk factors, and their apparent implications are explained through HIV opportunistic CNS pathologies. CNS toxoplasmosis and CNS lymphoma are very strong risk factors of new onset seizures in HIV infected patients. The role of multifocal progressive leukoencephalopathy and HIV unrelated pathologies, though not to be doubted, appear to be much smaller. The implication of HIV by itself appears weak, if at all, and the elucidation of its role would require further well designed cohort or case-control studies in which the diagnosis of HIV encephalopathy would be done on a neuropathological basis in cases as well as in controls, a condition very difficult to fulfil in common clinical practice.

GABRIEL GASPAR MARIA LUISA ÁLVAREZ HIV Unit, Internal Medicine Service, Hospital Universitario de Getafe,

Madrid, Spain

Correspondence to: Dr D Gabriel Gaspar, $\mathrm{C} /$ Cerro de los Perdigones n ${ }^{\circ}$, p-3, bajo 28224 Pozuelo de Alarcón, Madrid, Spain
1. Garg RK. HIV infection and seizure. Postgrad Med 7 1999;75:387-90.

2 Centers for Disease Control. 1993 Revised classification system for HIV infection and expanded surveillance case definition for AIDS among adolescents and adults. MMWR Morb Mortal Wkly Rep 1992;41:RR-17.

The author responds:

I am grateful to Dr Gaspar and Dr Álvarez for their interest shown in my article. In their study Gaspar and Alvarez observed that HIV related CNS opportunistic infections (for example toxoplasmosis) and CNS lymphoma were strong risk factors of new onset seizures in HIV infected patients. An almost similar observation was made by Rothman et al. ${ }^{1}$ In their study these authors tried to determine which neurological signs or symptoms were predictive of new focal lesions on a cranial computed tomography study in HIV infected patients, ${ }^{1}$ and 110 patients who had new or changed neurological signs or symptoms were subjected to cranial computed tomography. Twenty seven patients $(24 \%)$ had focal cerebral lesions seen on computed tomography of which $19(18 \%)$ were new lesions. New onset seizures were the most important clinical finding and were strongly associated with new abnormalities seen on computed tomography. In this study also the most common intracranial lesion among patients with CD 4 counts $1<200$ cells/ml was toxoplasmosis, while cerebrovascular accidents (ischaemic or haemorrhagic) were most common in those with CD 4 counts $>200$ cells $/ \mathrm{ml}$. So, I agree with Gaspar and Alvarez that HIV infected patients who have new onset seizures are more likely to have a definite focal abnormality, which in majority of cases are caused by readily treatable opportunistic CNS infections.

Another important point raised by Gaspar and Álvarez is about the role of direct HIV infection of the brain in the pathogenesis of new onset seizures in patients with AIDS. It has been suggested that in patients with seizures who have no definite identifiable disease of the brain, cerebral HIV infection seems to be the most likely cause of seizures. In a series by Wong et al 17 patients within the "non-identified" group (comprising of 32 patients) underwent postmortem examination of brain; only six of them had characteristic pathological changes suggestive of HIV encephalopathy. ${ }^{2}$ So, in all HIV infected patients with normal imaging studies and normal cerebrospinal fluid examination the seizures can not be attributed to HIV infection of brain. In a recent prospective study Pascual-Sedano et al reported that in the majority of such patients the new onset seizures were either because of antiviral drug toxicity or were related to some metabolic

Table 2 Results of univariate and multivariate analysis of hypothetical risk factors of new onset seizures in our HIV infected patients

\begin{tabular}{|c|c|c|c|c|c|c|c|c|}
\hline \multirow[b]{3}{*}{ Risk factor } & \multicolumn{4}{|c|}{ Univariate (Fisher's exact test) } & \multicolumn{4}{|c|}{ Multivariate (logistic regression) } \\
\hline & \multirow[b]{2}{*}{$O R$} & \multicolumn{2}{|l|}{$95 \% C I$} & \multirow{2}{*}{$\begin{array}{l}\text { p Value } \\
\text { (Fisher's) }\end{array}$} & \multirow[b]{2}{*}{$O R$} & \multicolumn{2}{|l|}{$95 \% C I$} & \multirow{2}{*}{$\begin{array}{l}p \text { Value } \\
(L L R)\end{array}$} \\
\hline & & Minimum & Maximum & & & Minimum & Maximum & \\
\hline CD $4+$ count $(<200 v \geqslant 200$ cells $/ \mathrm{ml})$ & 7.49 & 2.18 & 25.78 & 0.000 & 1.94 & 0.35 & 10.81 & 0.434 \\
\hline HIV infection clinical stage ( $\mathrm{C} v \mathrm{~B}$ or $\mathrm{A})$ & 4.05 & 1.68 & 9.74 & 0.001 & 1.24 & 0.26 & 5.92 & 0.788 \\
\hline CNS toxoplasmosis & 21.17 & 5.92 & 75.75 & 0.000 & 46.91 & 8.69 & 253.16 & 0.000 \\
\hline CNS lymphoma & 17.72 & 2.12 & 148.00 & 0.001 & 29.94 & 2.67 & 336.04 & 0.001 \\
\hline HIV encephalopathy & 3.43 & 1.03 & 11.34 & 0.050 & 4.74 & 0.91 & 24.56 & 0.070 \\
\hline Progressive multifocal leukoencephalopathy & 4.72 & 0.84 & 6.60 & 0.075 & 15.11 & 2.22 & 102.62 & 0.004 \\
\hline CNS pathologies not related to HIV & 3.43 & 1.03 & 11.34 & 0.050 & 8.18 & 1.88 & 35.66 & 0.006 \\
\hline Sex (female $v$ male) & 0.41 & 0.17 & 0.99 & 0.051 & 0.57 & 0.15 & 2.25 & 0.415 \\
\hline Age (for each year of increasing age) & 0.98 & 0.92 & 1.05 & 0.619 & 0.96 & 0.87 & 1.05 & 0.389 \\
\hline
\end{tabular}

$\mathrm{OR}=$ odds ratio $\mathrm{CI}=$ confidence interval $\mathrm{LLR}=$ logarithm of the likelihood ratio. 
derangement. ${ }^{3}$ Even in patients with definite HIV encephalopathy whether seizures are caused by direct HIV infection of brain or some associated toxic/metabolic abnormality remains to be established. I agree with Gaspar and Álvarez that a well designed cohort or case-control study of neuropathologically proved HIV encephalopathy patients with seizures or without seizures is required to establish the role of direct HIV infection of brain in the aetiopathogenesis of new onset of seizures in these patients.

1 Rothman RE, Keyl PM, McArthur JC, et al. A decision guideline for emergency department utilization of noncontrast head computed tomography in HIV-infected patients. Acad Emerg Med 1999;6:1010-16.

2 Wong MC, Suite NDA, Labar DR. Seizures in human immunodeficiency virus infection. Arch Neurol 1990;47:640-2.

3 Pascual-Sedano B, Iranzo A, Marti-Fabregas J, et al. Prospective study of new-onset seizures in patients with human immunodeficiency virus infection: etiologic and clinical aspects. Arch Neurol 1999;56:609-12.

\section{Medical restrictions to driving: awareness of patients and doctors}

EDITOR,-We were interested to read the article by Kelly et al on the awareness of patients and doctors of medical restrictions to driving published recently. ${ }^{1}$ It reported that "Doctors' knowledge of current licensing policy and action to be taken if a patient was not eligible to drive was poor".

This led us to conduct our own research among hospital doctors, general practitioners (GPs), and medical students. We used the doctors' questionnaire from the study by Kelly et al to investigate local knowledge of driving restrictions. We interviewed 50 hospital doctors from a variety of specialties (14 house officers, 12 senior house officers, 14 registrars, and 10 consultants) at the Queen Elizabeth Hospital, Birmingham; 23 GPs from five different practices around Birmingham with experience ranging from GP registrar to those qualified 30 years; and 30 fourth year medical students. Participation was voluntary and anonymous.

Our results were similar to those reported by Kelly et al. Knowledge of the age at which licences should be reviewed for fitness to drive was generally around the correct age of 70 years (see table 1 ).

When asked to name conditions that should be reported to the Driving Vehicle Licence Authority (DVLA) epilepsy, stroke,

Table $1 \quad$ Knowledge of age at which licences should be reviewed for fitness to drive

\begin{tabular}{lll}
\hline & $\begin{array}{l}\text { Mean age for } \\
\text { licence review } \\
\text { (years) }\end{array}$ & $\begin{array}{l}\text { Range of } \\
\text { answers given } \\
\text { (years) }\end{array}$ \\
\hline GPs & 69.2 & $27-80$ \\
Hospital doctors & 67.5 & $16-80$ \\
Medical students & 67.6 & $18-85$ \\
\hline
\end{tabular}

\section{Addison's disease in type 1 diabetes, presenting with recurrent hypoglycaemia"}

EDITOR,-Although medical intervention can be deleterious when diabetes mellitus coexists with other endocrinopathies, as shown by increased susceptibility to insulin related hypoglycaemia in the case reported above, ${ }^{1}$

Table 2 Knowledge of specific restrictions

\begin{tabular}{lccc}
\hline \multirow{2}{*}{ Condition } & \multicolumn{2}{c}{$\%$ Of correct complete advice (\% of correct but incomplete advice) } \\
\cline { 2 - 4 } & GPs & Hospital doctors & Medical students \\
\hline Epilepsy & $4(43)$ & $14(26)$ & $0(43)$ \\
Stroke & $13(26)$ & $2(26)$ & $0(13)$ \\
Myocardial infarction & $35(0)$ & $16(0)$ & $7(0)$ \\
Abdominal aortic aneurysm $>5 \mathrm{~cm}$ & $26(0)$ & $41(0)$ & $13(0)$ \\
Diabetes mellitus & $0(52)$ & $0(48)$ & $0(23)$ \\
\hline
\end{tabular}

the converse is also true that treatment of metabolic crisis can occasionally prove to be equally beneficial for diabetic decompensation and for coexisting unsuspected endocrinopathy other than Addison's disease. This is illustrated by an 81 year old woman admitted with diabetic decompensation characterised by a plasma glucose concentration of $35.1 \mathrm{mmol} / 1$, urea $32.2 \mathrm{mmol} / 1$, creatinine $164 \mu \mathrm{mol} / \mathrm{l}$, and bicarbonate 24 $\mathrm{mmol} / \mathrm{l}$, in the presence of Escherichia coli septicaemia. By day 17 , as a result of treatment with intravenous fluids, insulin infusion, and antibiotics, she was much improved, with random blood glucose of 3.1 $\mathrm{mmol} / \mathrm{l}$, urea $8.9 \mathrm{mmol} / \mathrm{l}$, creatinine 142 $\mu \mathrm{mol} / \mathrm{l}$, and she was subsequently discharged home. What had been overlooked, in the preoccupation with her diabetic status, was that plasma calcium concentrations on day 1 and on day 17 were $3.6 \mathrm{mmol} / \mathrm{l}$, and 2.64 $\mathrm{mmol} / \mathrm{l}$, respectively (unsolicited, therefore not perceived!), and that emergency treatment of diabetes, using large amounts of intravenous fluids, had been of equal benefit for diabetes and for coexisting hypercalcaemia. The latter, on subsequent investigation, proved to be attributable to primary hyperparathyroidism (characterised by a serum parathyroid hormone level of $75 \mathrm{pg} / \mathrm{ml}$ (reference range $11-55 \mathrm{pg} / \mathrm{ml}$ ), in the presence of a plasma calcium of 2.94 $\mathrm{mmol} / \mathrm{l}$, with concurrent plasma albumin of $30 \mathrm{~g} / 1)$.

\section{Comment}

The prevalence of diabetes mellitus may be as high as $7.8 \%$ among patients with proven primary hyperparathyroidism, ${ }^{2}$ either as a result of the fact that, since both type 2 diabetes and primary hyperparathyroidism are age related, ${ }^{34}$ their prevalence in old age might be sufficiently high to result in their coexistence by pure chance, or because hypercalcaemia can be complicated by insulin resistance. ${ }^{5}$ Support for the latter theory comes from the case report of a 56 year old woman presenting simultaneously with type 2 diabetes and primary hyperparathyroidism, in whom parathyroidectomy resulted in reversal of glucose intolerance. This therapeutic "coup" was validated by the fact that, postoperatively, having discontinued her antidiabetic medication (gliclazide) for three months as a result of excellent control (characterised by glycated haemoglobin of $4.6 \%$ ), a subsequent $75 \mathrm{~g}$ oral glucose tolerance test yielded normal results. ${ }^{6}$

O M P JOLOBE

Department of Medicine for the Elderly, Tameside General Hospital, Fountain Street, Ashton under Lyne OL6 9RW, UK

1 McAulay V, Frier BM. Addison's disease in type 1 diabetes presenting with recurrent hypoglycaemia. Postgrad Med f 2000;76:230-2.

2 Taylor WH. The prevalence of diabetes mellitus in patients with primary hyperparathyroidism and amongst their relatives. Diabet Med 1991;8: 683-7.

3 Meneilly GS, Tessier D. Diabetes in the elderly. Diabet Med 1995;12:949-60.

4 Habener JF, Potts JT. Primary hyperparathyroidism. In: DeGroot LJ, Besser G, Cahill GF, eds. Endocrinology. Philadelphia: WB Saunders, 1989: chapter 58.

5 Kim H, Kalkhoff RK, Costrini NV, et al. Plasma insulin disturbances in primary hyperparathyroidism. F Clin Invest 1971;50:2596-605.

6 Qiun JD, Gumpert JRW. Remission of nonQiun JD, Gumpert JRW. Remission of non-
insulin-dependent diabetes mellitus following insulin-dependent diabetes mellitus following
resection of parathyroid adenoma. Diabet Med resection of parath
1997;14:80-1. 


\section{BOOK REVIEWS}

The reviewers have been asked to rate these books (or CD-ROMs) in terms of four items: readability (or technical quality), how up to date they are, accuracy and reliability, and value for money, using simple four point scales. From their opinions, we have derived

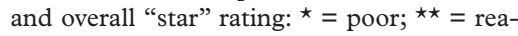
sonable; ${ }^{\star \star \star}=$ good; ${ }^{\star \star \star \star}=$ excellent.

Bedside Cardiology. Edited by Jules Constant. (Pp 342; \$49.95 paperback.)

Lippincott Williams \& Wilkins, 1999. ISBN 0-7817-2168-7. ${ }^{\star \star \star}$

The fifth edition of Bedside Cardiology is a refreshing educational read to all training in cardiology as well as established consultants in cardiology and those with an interest in the subject. Dr Constant is Associate Clinical Professor at the State University of New York at Buffalo. He clearly is an expert clinician. This book has a unique style incorporating what the author calls the Socratic method of teaching. The information is presented very much as a question and answer format for programmed learning.

Cardiac diagnosis in recent years has tended to become more focused on accurate non-invasive investigations rather than an in-depth precise clinical bedside diagnosis. This book would tend to redress that trend and focus the emphasis again an accurate examination. Anyone teaching medical students or postgraduate students would greatly enhance their diagnostic acumen with a careful examination of this book. The author emphasises many important aspects of a clinical examination and educationally the discussion of false positive and false negative signs that every technology suffers from is particularly valuable.

I found this a highly educational and exciting book to read. The author has a style which attracts you to constantly read every section and it is very difficult to skim any section for fear of losing valuable information.

The chapters on the jugular venous pressure and arterial pulses are particularly educational.

This book is essential reading for all those involved in clinical cardiology, not only to enhance their own diagnostic acumen but also to refresh their knowledge, enabling them to become better teachers of the bedside manner of diagnosing and teaching cardiology.

D J COLTART Consultant Cardiologist/Clinical Director Cardiothoracic Unit, St Thomas's Hospital, London,

Instant Notes in Immunology. By P M Lydyard, A Whelan, M W Fanger. (Pp 318; $£ 14.95$ paperback.) Bios Scientific Publish-

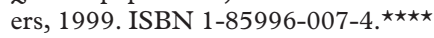

I recommend this new short soft backed immunology textbook to both medical students and to those studying for their respective collegiate examinations. A major advantage of the format of this book is that it allows one to find essential pockets of information that in many other immunology books are disseminated throughout the text and hence difficult to extract. The key notes at the start of each chapter are good revision/overview statements. This is not a clinical immunology book, but it does apply basic mechanisms to clinical situations in the applied chapters. The 120 multiple choice questions at the end of the book will be particularly welcomed by candidates for collegiate examinations as there is a lack of quality published multiple choice questions in the field of immunology.

At $£ 14.95$ this book is a worthy investment for those interested in expanding their knowledge of immunology.

R J POWELL Clinical Immunology Unit, Queen's Medical Centre, Nottingham, UK

Lee's Synopsis of Anaesthesia. 12th Ed. G B Rushman, N J H Davies, J N Cashman. (Pp 750; 27.50.) Butterworth Heinemann, 1999. ISBN 0-7506-3247-X. ${ }^{\star \star \star \star ~}$

The 12th edition of this book is a mine of information. The sections on history and intensive care medicine will be missed, but it does allow the book to be easily portable again. The book, having been read once, will be used to revise, and subsequently to refer to time and time again.

The trainee anaesthetist will obviously need to undertake wider reading. For example, the section on acid-base balance is excellent from which to revise, but perhaps difficult to learn from. The synopsis has justifiably strict criteria for accepting patients for daycase surgery, but some anaesthetists may not be so strict. In further reading the anaesthetists will be assisted by the excellent references at the end of each chapter.

The chapter on obstetric anaesthesia is most comprehensive. The section on regional analgesia is a great reference section with clear unequivocal descriptions of techniques. The brief final section on statistics is most helpful.

The chapter on rare diseases will be of great use when the anaesthetist is confronted with a patient only an hour or two before an operation, who is suffering from a rare condition.

Lee's Synopsis of Anaesthesia is a textbook to have at hand and will prove invaluable to those in training, those recently trained, and those anaesthetists old enough to have been examined by J Alfred Lee himself. I can well remember being asked to tell him all I knew about Di Vinyl Ether!

$\mathrm{N}$ W KING Consultant Anaesthetist, Leicester General Hospital, UK

Benefits and Hazards of Exercise. Edited by Domhnall MacAuley. (Pp 384; 35.00 .) BMJ Publishing Group, 1999. ISBN 0-7279-1412-X. ${ }^{\star \star \star \star ~}$

The stated aim of this book is to be a "must for all of us who are involved in promoting physical activity and advising people who are interested in exercise". Its target audience is diverse and includes specialists in sports medicine, general practioners, sports scientists, and trainers. Individual chapters cover most aspects of exercise and range from a general overview of the methods of promoting physical activity in primary care to the specific problems of altered reproductive function in endurance athletes and the physiological adaptations of altitude training. There are excellent chapters on exercise and diabetes and exercise and hypertension, with a chapter concentrating on the important interaction between exercise and psychological well being. Concise summaries are provided for all chapters and the most important learning points are highlighted in boxes. Multiple choice questions are also provided at the end of each chapter which allow the reader to test their knowledge. The book is well referenced and up to date, but deficiencies in the literature are acknowledged by the authors.

Anyone with an interest in sports medicine will find something in this book to interest them. It is well written and provides a concise yet comprehensive overview of the benefits and hazards of exercise.

R ROBINSON Glenfield NHS Trust, Leicester, UK

Guide to Working in Europe for Doctors. By K E A Darling. (Pp 226; £19.95.) Churchill Livingstone, 2000. ISBN 0-44306281-1..$^{\star \star \star \star}$

The first section comprises three chapters The first chapter is a brief but insightful history of the origins of a united Europe, the administrative bodies, how legislation is passed, and the implications for healthcare professionals. Chapter 2 focuses on the differences between EU member states by region: English speaking countries (UK and Republic of Ireland), Benelux countries (Belgium, the Netherlands, and Luxembourg), French speaking countries (France, Belgium, Switzerland (although not part of the European economic area), and Luxembourg), German speaking countries (Germany, Austria, Switzerland, and Luxembourg), Norden (Denmark, Finland, Iceland, Norway and Sweden), and Southern Europe (Spain, Portugal, Italy, and Greece). The organisation of healthcare systems, education and clinical training, terms and conditions of employment, practical differences in the workplace, recognised qualifications and examination grades, culture, and ethics are all outlined. In the third chapter the practical points of moving abroad are covered including two valuable checklists, the costs of moving abroad and planning a move.

The second section comprises details relevant to the 19 individual countries, including the United Kingdom.

Obviously this book should be in every medical library. But would it be a worthwhile investment for someone who is going to work in Europe, especially as they will usually only be working in one country? The first section, of 43 pages, provides such a wealth of general information and advice, and the specific information provided about the country to which you intend to move and the others is so interesting, that the answer is "Yes."

Oh, and whatever you do, ensure that you have the necessary qualifications, or can acquire the recognised equivalents abroad, such that you can return to your home country-comprehensive recognition of qualifications throughout Europe is not yet with us.

PHILIP D WELSBY

Consultant Physician, Western General Hospital, Edinburgh, UK 


\section{CD-ROM REVIEW}

Blood Pressure Measurement. Produced by the British Hypertension Society. BMJ Publishing Group; $£ 47.00$. ISBN 0727-

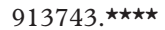

This CD-ROM specifies on its outside cover, in some detail, the minimum system requirements. These will not be met by all equipment currently in use in medical libraries nor by bottom of the range home computing. The technical qualities of the CD-ROM are excellent. It is easy to read, the sound production is clear (perhaps a little loud for use in library computer rooms), and it is user friendly. The content reflects current British Hypertension Society (BHS) guidelines and includes, in addition to historical notes, relevant explanation of different techniques used in incorporating ambulatory blood pressure measurement, measurement in special populations, and finally the rudiments of equipment evaluation.

The main features are detailed instructions in the technique of blood pressure measurement, pointing out common pitfalls and self testing sequences of falling mercury and Korotkov sounds. The anticipated audience ranges from junior nurses to senior physicians whose digit preferences and habitual methodological errors need ironing out. The material presented is up to date and lends itself to use in learning and assessment tutorials geared to the level of the learner group. The failure of the BHS measurement group to come up with unequivocal recommendations for standard sphygmomanometer cuff bladder dimensions will limit the shelf life of the BHS production and limits this reviewer's value for money verdict to a recommendation of purchase by institutions rather than individuals.

J E F POHL Consultant Cardiologist, Leicester General Hospital, Leicester, UK

\section{Falk Symposia}

1-2 October 2000: Non-neoplastic diseases of the anorectum - an interdisciplinary approach (Freiburg, Germany)

3-4 October 2000: Immunosuppression in inflammatory bowel diseases-standards, news, and future trends (Freiburg, Germany) 12-13 October 2000: Biology of bile acids in health and disease (Den Haag, The Netherlands)

4 November 2000: Chronic inflammatory bowel diseases - progress and controversies at the turn of the century (Bucharest, Romania) Details: Falk Foundation eV-Congress Division, Leinenweberstr 5, PO Box 6529, D-79041 Freiburg, Germany (tel: +49 (0) 761 130340, fax: +49 (0) 761 1303459, email: symposia@falkfoundation.de).

\section{Ninth International Symposium on} celiac disease

10-13 August 2000: Hunt Valley, MD, USA Details: Althea Pusateri, Program Coordinator, University of Maryland School of Medicine, $655 \mathrm{~W}$ Baltimore Street, Baltimore, MD 21201, USA (tel: +1 410706 3957, fax: +1 410706 3103, web site: http:// www.celiaccenter.org).

\section{Royal College of Physicians of Edinburgh}

2-15 September 2000: Healthcare for older people - the UK experience (course)

7-8 October 2000: Stroke treatment and service delivery (consensus conference)

Details: Education, Audit, and Research Department, Royal College of Physicians of Edinburgh, 9 Queen Street, Edinburgh EH2 1JQ, UK (tel: +44 (0) 1312257324 , fax: +44 (0) 131220 4393, web site: www.rcpe.ac.uk).
Royal College of Physicians of Edinburgh/Scottish Intercollegiate Guidelines Network

3 November 2000: Symposium on clinical effectiveness, clinical guidelines and clinical standards

Details: Mrs Anne Fairbairn, Coordinator for Research and EBM, Royal College of Physicians of Edinburgh, 9 Queen Street, Edinburgh EH2 1JQ, UK (email: a.fairbairn@rcpe.ac.uk).

\section{3rd Teupitz Colloquium}

17-20 September 2000: Basic Research in Endocrine Dermatology

Details: Professor $\mathrm{Dr}$ Ch C Zouboulis, Department of Dermatology, University Medical Center Benjamin Franklin, Free University of Berlin, Hindenburgdamm 30, 12200 Berlin, Germany (tel: +49 30844528 08, fax: +49 $30 \quad 84 \quad 4542$ 62, email: zoubbere@zedat.fu-berlin.de).

\section{St Mark's Hospital \& Academic Institute}

16-18 October 2000: Frontiers in colorectal disease (lecture course)

Details: The Administrator, St Mark's Academic Institute, St Mark's Hospital, Northwick Park, Harrow, Middlesex HA1 3UJ (tel: +44 (0) 208235 4046/8, fax: +44 (0) 20 8235 4039, email: e.power@ic.ac.uk; web site: www.stmarkshospital.org.uk).

\section{CORRECTION}

Iron deficiency anaemia-a clinical challenge

We regret that an error occurred in the above editorial by Wurm and Wicks in the April issue (2000;76:193-4). In referring to a related paper in the same issue by Willoughby and Laitner (2000;76:218-22) the name of Dr Laitner was inadvertently misspelt.

Our apologies to Dr Laitner. 